\title{
Effects of Chinese Areas in Globalization__ Under Metrolingualism
}

\author{
Zeyu Wang \\ Room3514, NO.3, Bangzijing Apartment, NO.2, Jianguo Rd. Chaoyang District, China \\ db15wzy@cuc.edu.cn
}

Keywords: Chinese areas, Globalization, Communication, Metrolingualism.

\begin{abstract}
The urbanization of human material and physical material is not a new to globalized world. People are always not sensitive to any changes made to the spiritual and culture life. Metrolingualism is a sociolinguistics term to describe the languages in today's cities. It grabs people's attention to the things they use and work with every day. As the world's most widely distributed ethnic group, Chinese people and language have formed a number of Chinese areas around the world with much influence. Both positive and negative effects of Chinese areas in sociolinguistics paradigm are analyzed. A perspective on Chinese areas under Metrolingualism is described. The potential impact of languages and culture areas in globalization and communication is discussed. The key conclusion is based on a small-scale but in-depth fieldwork, means specifically in possible issues in globalization.
\end{abstract}

\section{Introduction}

"Cities and languages are in constant change, as new speakers with new repertoires come into contact as a result of globalization and the increased mobility of people and languages." (Pennycook \& Otsuji, 2015). Alastair Pennycook and Emi Otsuji (2015) defined term metrolingualism as the ways in which people of different and mixed backgrounds use, play with and negotiate identities through language, especially in the dynamic and the context of interaction. Metrolingualism, in short, emergent languages in the city, is the live broadcast of the process of globalization.

Chinese areas, as one of different language areas and ethnic precincts in cities, introduce the Chinese culture into the city and provide an interactive environment for diverse cultures. With rapid growth of Chinese economy, increased population mobility made the size of Chinese areas ranks behind only native and some former colony in urban Europe (Benton \& Pieke, 2016). While in terms of mobility and rhythm, Chinese areas tend to be closed externally and immobilized internally (Pennycook \& Otsuji, 2015). In some cities, it exists "alienation" between Chinese areas and other parts.

This essay will critically discuss the effects of Chinese areas in metrolingualism starting with a detailed overview of the Chinese areas in western cities. Subsequently it will analyze the status quo and possible issues during globalization based on ethnographic fieldwork. Further critical evaluation of the Chinese areas on their identity in cities will also be considered.

\section{Analysis of Chinese areas in metrolingualism}

According to Blue Book of Overseas Chinese (2016), it has more 60 million Chinese people distributed in over 198 countries and regions. Recent years, a great part of them resided in so-called western countries: North America, Europe, Australia, Japan and South Korea. Chinese areas appeared in almost all the major cities around the world. Historically, Chinese areas in western cities started since the middle of the 19th century. And after Chinese Reform and Opening, by virtue of Chinese population, Chinese areas occupied special places in western urban development.

Especially in the language involvement, the absolute size of Chinese areas is extensive. In some immigrant nations and cities, the number of Chinese users rank just after English. According to the 
2011 census of Australia, of the 21,194 inhabitants of Sydney Chatswood, about 41 per cent speak only English at home, while 59 per cent speak other languages at home, the most common being Mandarin Chinese (14 per cent) and Cantonese (13 per cent), more than half of other languages. (Pennycook \& Otsuji, 2015). Some scholar pointed out that the statistics are an underestimation, as they do not include those who have no one to speak their own language to at home (e.g. single inhabitants) and those who speak LOTEs (Language Other Than English) on a regular basis in other social spheres (parents, other relatives, neighbors or friends) (Lasagabaster, 2010). In the latest census 2016, there are 11 districts in Sydney where the proportions of Chinese are more than 25\%. And the highest share is closer to 50\% (Table 1). Australia has $2.5 \%$ and $1.2 \%$ people speak Mandarin Chinese and Cantonese at home nationwide, pointing to $1.6 \%$ and $1.2 \%$ growths respectively. (BBC Chinese,2017). In other words, among 24.4 million population, 1 of every 28 people in Australia speak Chinese at home. These growths are far outstripping the other nations of the world over the same period.

\begin{tabular}{lc} 
Table 1 Proportion of Chinese Population in Sydney \\
\hline Districts & Proportion (\%) \\
\hline Hurstville & 49.4 \\
Rhodes & 44.5 \\
Burwood & 45.1 \\
Chatswood & 34.1 \\
Eastwood & 38.4 \\
Allawah & 29.5 \\
Campsie & 31 \\
Ultimo & 36.6 \\
Haymarket & 31.9 \\
Homebush West & 25.5 \\
Wolli Creek & 31.1 \\
\hline Source: 2016 Census &
\end{tabular}

The rapid expansion of Chinese areas in western cities is also a particularly static representation of diversity. On such basis of population, Chinese areas are not only large ethnic precincts, rather communities provide language interactions with a different environment from local languages or English, which are lingua francas in western cities. Internally, the form of Chinese areas added oriental culture and elements into local culture and had local communities' structure reorganized (Zhou, 2009). Mature Chinese areas with a history, would get more of a say through political participation.

Such culture and language involvement also attracted local governments' attention. Some activities and festivals like Chinese culture week, "Chinese Bridge" contest, "Three Tours" activities, and To-China programs. Externally, the extend of Chinese areas and connection to other language areas are much abundant. To meet the diet and customs needs, Chinese and other Asian who have similar diet founded marketing network for Asian food in western cities. Drawing on these marketing network, Chinese people made a follow-up market for vegetables and other universe foods. In those markets, Chinese, sometimes alongside English as a sale language (Pennycook \& Otsuji, 2015).

In Sydney Central Market, Cantonese is a common language of interaction for the customers and sellers. Although, for most of them English is the default language of commercial transaction, Cantonese is the language of social interaction, especially when they have settle on a familiar language. And in Pennycook and Otsuji's research (2015) one informant asserted that Mandarin Chinese was in fact the lingua franca of the market. This claim appears to be a result of the widespread use of various Mandarin resources.

Apart from markets, other public places like café, restaurants, airports and tourist points, contained more and more Chinese elements. They become the dynamic Chinese areas. In Vienna, Austria, mobile operator provides the Chinese service; In Helsinki airport, there are guide signs and broadcasting in Chinese, and staffs who speak Chinese; in tourist points around Europe like Louvre, Colosseum, Hofburg and even in Arctic Circle Santa Claus's Village, audio guides and information desk offer Chinese options. In Budapest, Hungry, the realtor agency said they can speak Chinese. 


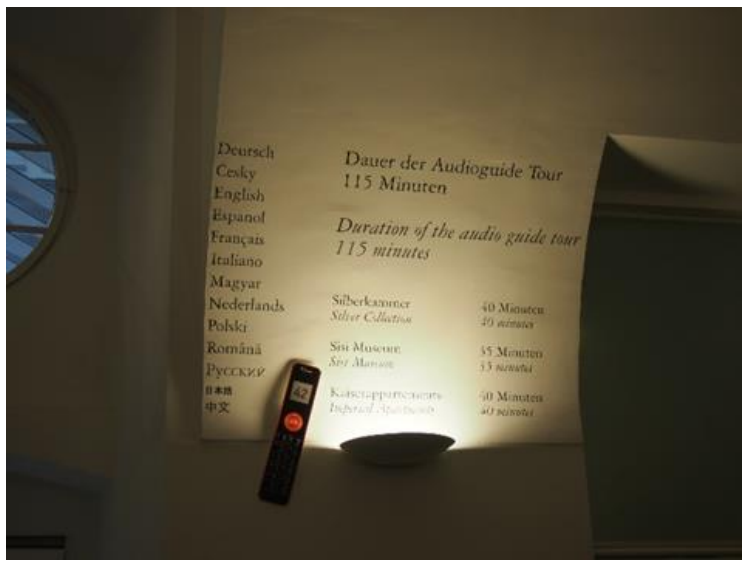

Fig. 1. Vienna Holfburg

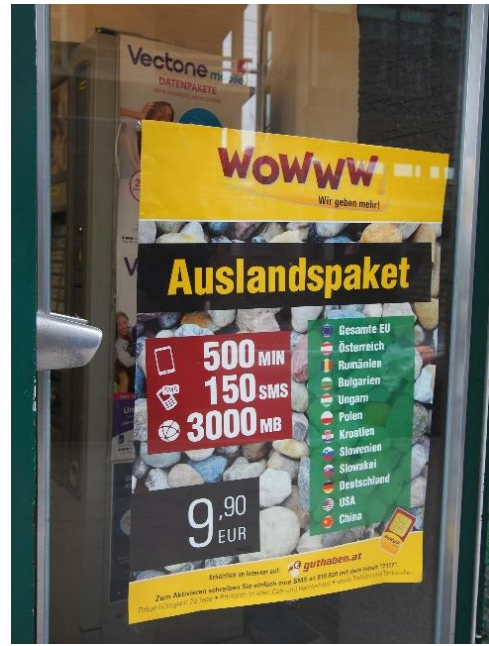

Fig. 3. Vienna Mobile Telecom Carrier

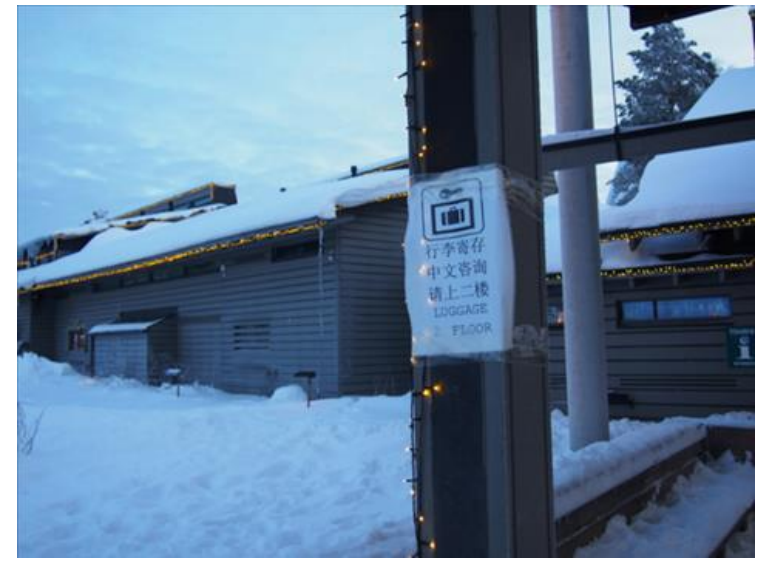

Fig. 2. Rovaniemi, Santa Claus Village

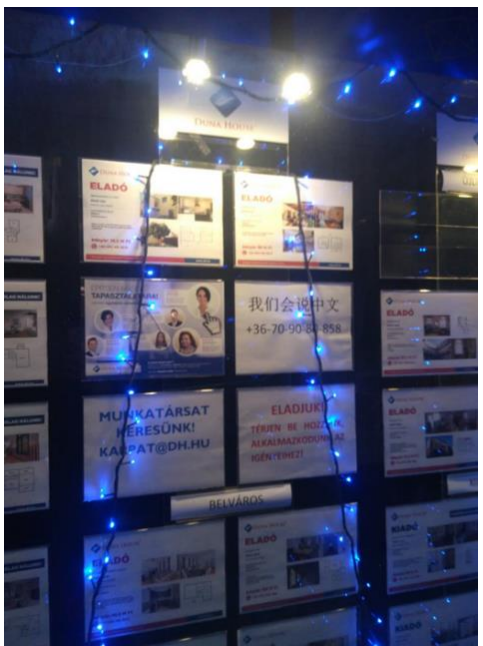

Fig. 4. Budapest, Realtor Agency

These dynamic Chinese areas show the influence of Chinese language in western language today. Chinese language to the West is of growing importance, not only as far as size and scale are concerned, but also with respect to the rise of China as a global economic player (Collins, 2007). For businesses, it maybe the strategy to attract China's growing consumers. However, it is shown by the results that Chinese areas have a positive effect to globalization and development of metrolingualism.

\section{Critical evaluation of the Chinese areas in metrolingualism}

"Different ethnic precincts may also keep different hours. Chinese areas of a city typically start later and continue much later than others." (Pennycook \& Otsuji, 2015). In Pennycook and Otsuji's research $(2010,2015)$, Chinese areas have representativeness and particularity in mobility, rhythms and cities. Historically, compared to other language areas or ethnic precincts, mature Chinese areas started later but developed rapidly, and once form, are in high cohesion and sustainability. To a certain degree, it reflects the Chinese areas' nature of closed. There is, suggested by western sociolinguist, a tendency that the more mature Chinese areas, the less globalization (Kinkead, 1992 \& Guest, 2003). Internally, the language uses inside Chinese areas are being singularized. The problem puzzled the second-generation Chinese immigration is that languages leads to a difficult identity of individuals. Unlike that of previous generations, they don't have the pressure of survival by languages. In Milan, Italy, with the im-provement in economic conditions, in some cases, the second-generation immigration grew up in China and were taken abroad at education ages. They cannot have a good family language education, most of them speak other than local languages at home. In addition, the infrastructures in Chinese areas are adequate for basic life. Besides learning at school, they do not have an Italian environment(Yan, Bao \& Zhen,2015).Similar situations may arise with the immigrations who are not highly skilled. They need no language qualifications by finding an easy job 
in Chinese areas.

Movements and mobility helps to understand the city and space. In order to understand the city, it need to appreciate that people are moving between places. The urban condition exists insofar as it is predicated on the space between these places. Only when humans are moving through the city, the size, diversity and difference can be felt (Pennycook \& Otsuji, 2015). In turn, immobilization can lead to conflicts between different areas. At the beginning of this century, both in London and Milan, top two large Chinese community around the world have conflicts with local authorities. On April 2007, growing tensions between Chinese entrepreneurs and Italian authorities, residents and shopkeepers finally resulted in a violent clash in Milan's Chinatown. Behind the seemingly economic dispute cases, is the integration issues with different societies (Hatziprokopiou \& Montagna).

The independence of Chinese areas in some western cities have raised ideas of China Threat. There exist publics see Chinatown as a colony of the East in the West (Anderson, as cited Cresswell,2006). Indeed, it is a vision of Chinese that tend to make foreign lands feel at home. Take Milan as an example, Chinese areas in Milan is nearly a self-sufficient community. According to Italian Central Institute of Statistics (ISTAT) (2015), there are around 63000 legal Chinese residents in Milan, and most of them live in Paolo Sarpi, the Chinatown. The industries in Chinatown include almost all professions: apartments, restaurants, markets, entertainments, primary schools and even regular hospitals. These infrastructures, except Chinese restaurants, pitched to same customer inside the Chinese areas, in other word, Chinese itself.

Following stores' names and advertisements are only in Chinese and with Italian address as directions. And if without those Italian address and guide signs, it easily to thought was China not Italy. "Cities should be seen less as places of distinct communities marked by clear and fixed boundaries but rather as local public spheres with multidimensional connections that overlap and conflict." (Wood and Landry, 2008). Chinese areas in Milan use Chinese to make an invisible boundary.

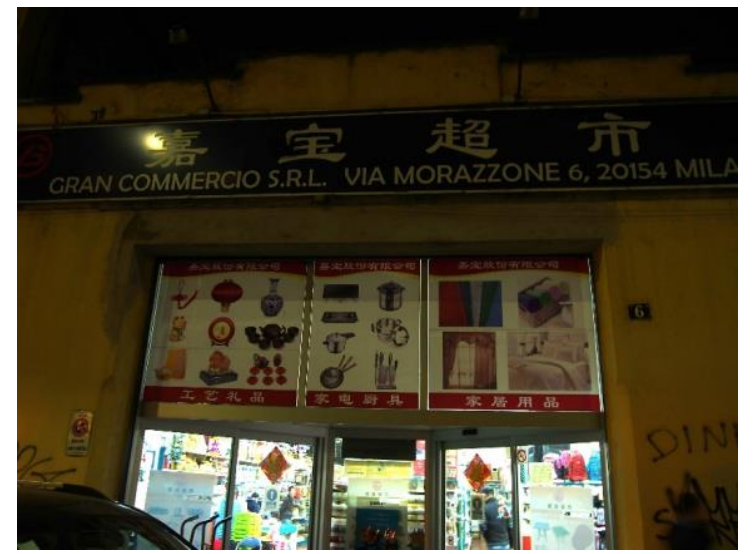

Fig. 5. A Chinese Grocery store

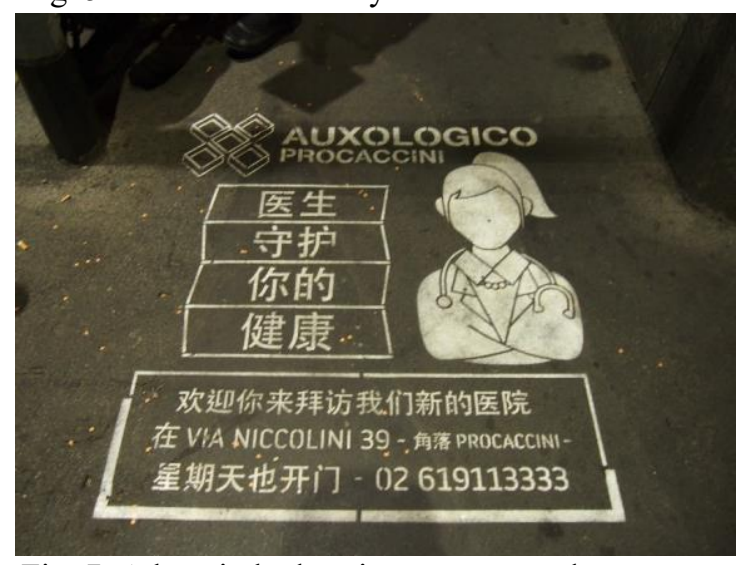

Fig. 7. A hospital advertisement on road

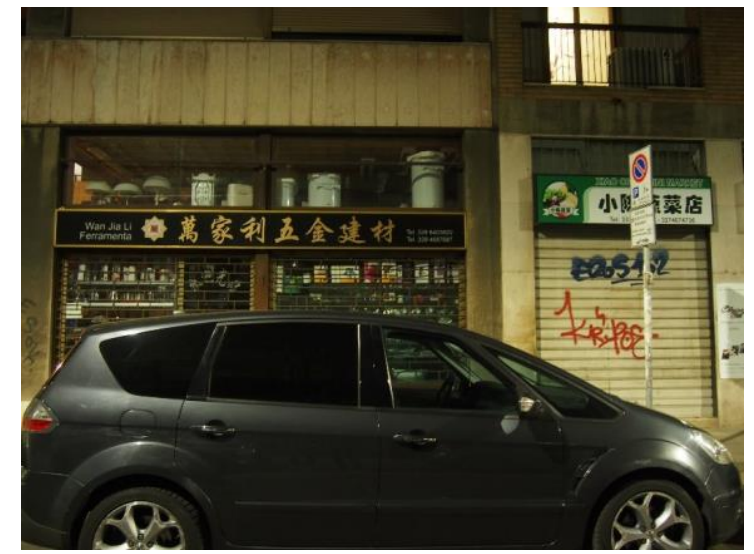

Fig. 6. A hardware store and Vegetable store

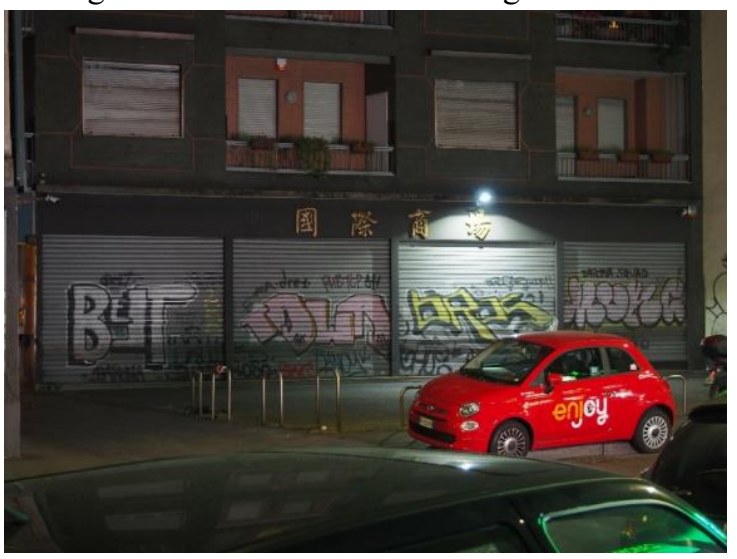

Fig. 8. International Market in Chinatown 
Chinese restaurants, as one of essential symbols for both physical and cultural level, also have a pattern depends on the locations. (Table 2)

\begin{tabular}{|c|c|c|c|c|c|}
\hline Cities & Location & Names & Staff Structure & Payment Ways & Aimed Cusumers \\
\hline Helsinki & City Centre & $\begin{array}{l}\text { Flowercity } \\
\text { Resaturant } \\
\text { (花城饭店) }\end{array}$ & has 1 Singaporean & Cash or Cards & $\begin{array}{l}\text { All customers, } \\
\text { mainly foreigners }\end{array}$ \\
\hline Stockholm & City Centre & $\begin{array}{l}\text { Chopsticks } \\
\text { (富都阁) }\end{array}$ & has 1 Swede & Cash or Cards & $\begin{array}{l}\text { All customers, } \\
\text { mainly foreigners }\end{array}$ \\
\hline Prague & Tourist Point & $\begin{array}{l}\text { Mongolian BBQ } \\
\text { (蒙古烧烤) }\end{array}$ & $\begin{array}{l}\text { has } 1 \text { Vietnamese, } \\
1 \text { Indonesian }\end{array}$ & Cash or Cards & All customers \\
\hline Berlin & Residential Areas & $\begin{array}{l}\text { China Resturant } \\
\text { (俊妞面馆) }\end{array}$ & Chinese family & $\begin{array}{l}\text { Only cash } \\
\text { or debit card }\end{array}$ & $\begin{array}{l}\text { All customers, } \\
\text { mainly Asian }\end{array}$ \\
\hline Milan & Chinese Areas & $\begin{array}{l}\text { Restuante Chinese } \\
\text { (糞海酒家) }\end{array}$ & Chinese family & Cash only & $\begin{array}{l}\text { All customers, } \\
\text { mainly Chinese }\end{array}$ \\
\hline
\end{tabular}

Chinese restaurants in downtown or tourist points are more international both in names and staff structures with meaningful English names and foreign waiters. Near the central business district, they all accept card-based payments including credit cards. In order to attract local consumer and foreigners, the menus are designed in at least three languages (local languages, English and Chinese). The business strategy of Flowercity restaurant in Helsinki and Chopsticks in Stockholm, mainly introduce Chinese buffet, which easily for free choices without understanding of lengthy explanations. Chinese restaurants opened at residential areas are mainly for regular clients. They have stable manage strategies and run by a single family. Asian residents are a part of patronage because of the similar diet. The restaurants in mature Chinese areas usually asked for cash only, and cash flows in an inner loop of Chinese areas. Their customers are mainly Chinese people who travel abroad or Chinese people live in cities, on a lower scale just the Chinese people work or live inside Chinatown.

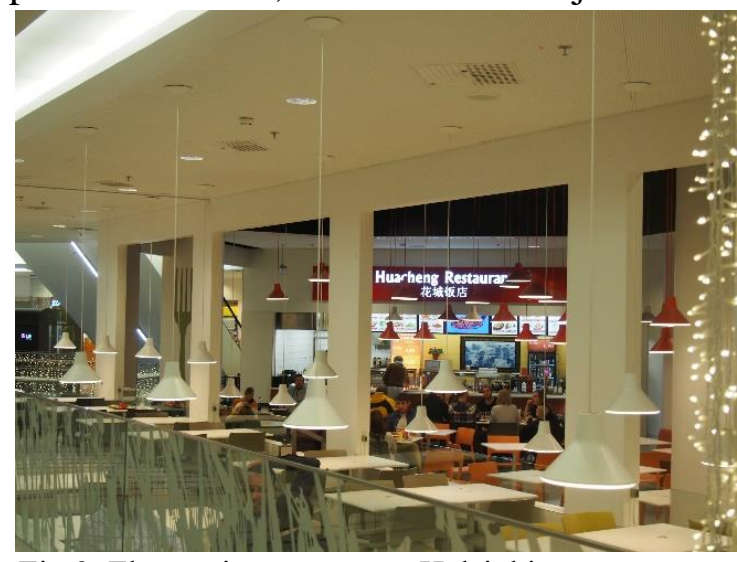

Fig.9. Flowercity restaurant, Helsinki

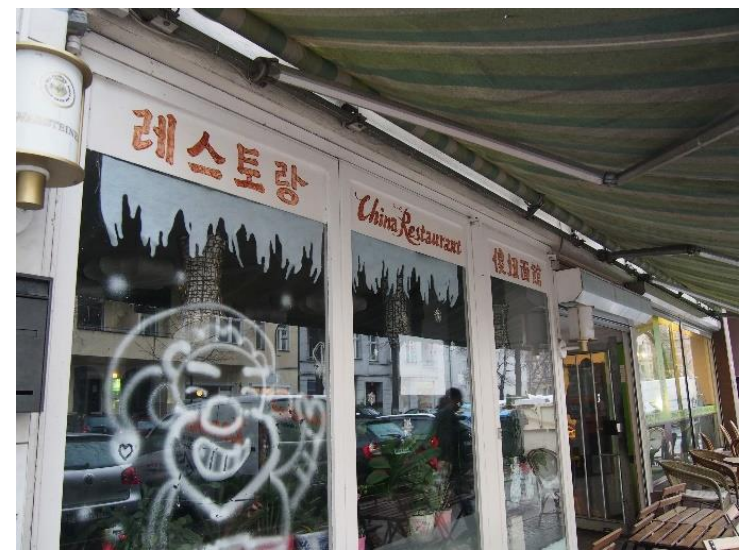

Fig. 11. China restaurant, Berlin

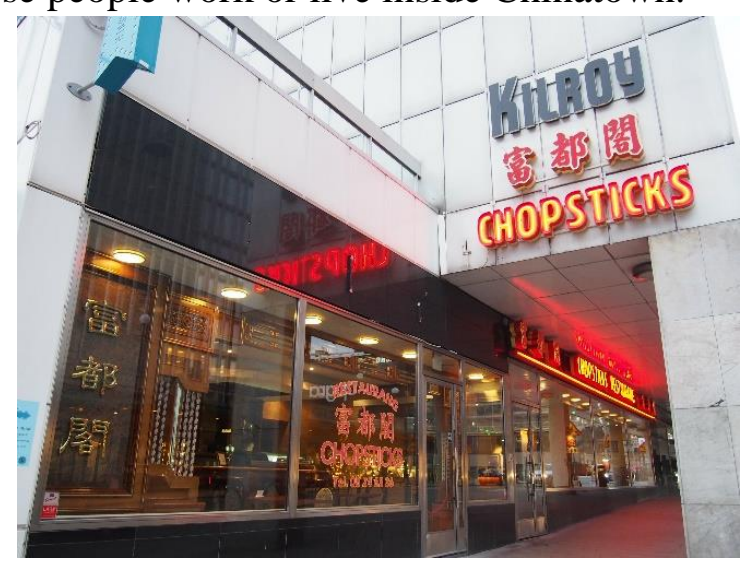

Fig. 10. Chopsticks, Stockholm

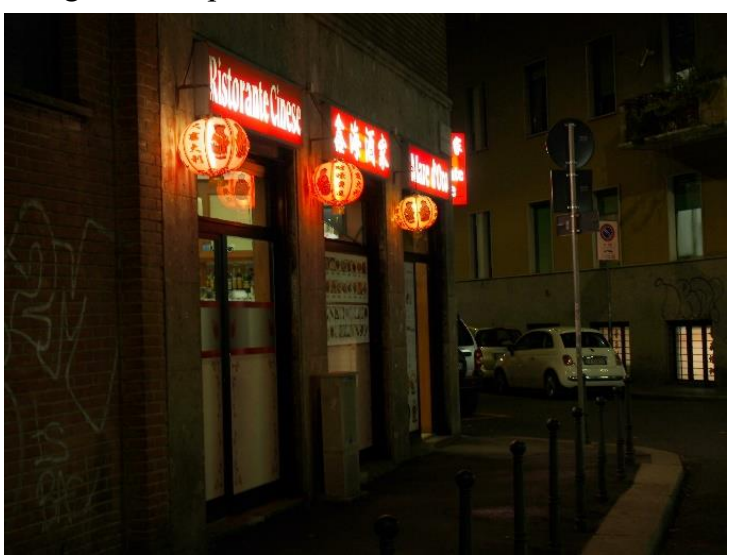

Fig. 12. Restaurante Chinese, Milan

In today's trend of globalization, Chinese areas exist reverse to close themselves, which also deviate the intension. 


\section{Conclusion}

In conclusion, Chinese areas in western cities play an important role in the processes of globalization. On the positive side for globalization, Chinese areas can accommodate much more interactions of languages and cultures drawing on their size and scale. And as it is shown above, the influence of Chinese is not only confined to China and Southeast Asian countries. Along with the economic takeoff of China and immigrations, an increasing number of western cities have been affected by this ancient language. Chinese areas have promoted the harmony of eastern and western culture and the pluralism all over the world. They play essential roles in cities, where the places of diversity, of rhythms and layers. They are not simple ethnic precincts. Meanwhile, for globalization, Chinese areas also exist negative effects on its mobilities and materialities. The close nature of Chinese itself can lead to an immobilized loop and conflicts with others. It seems pretty clear that Chinese areas in western cities are worthy of attention.

\section{References}

[1] Anderson, K. J. (1991). Vancouver's Chinatown: racial discourse in Canada, 1875-1980. McGill-Queen's Press-MQUP.

[2] Benton, G., \& Pieke, F. N. (Eds.). (2016). The Chinese in Europe. Springer. Collins, J. (2007). Ethnic precincts as contradictory tourist spaces. Tourism, ethnic diversity and the city, 52-67.

[3] Collins, J., \& Kunz, P. (2009). Ethnicity and public space in the city: Ethnic precincts in Sydney. Cosmopolitan Civil Societies: An Interdisciplinary Journal, 1(1).

[4] Cresswell, T. (2006). On the move: Mobility in the modern western world. Taylor \& Francis.

[5] Guest, K. J. (2003). God in Chinatown: Religion and survival in New York's evolving immigrant community. NYU Press.

[6] Kinkead, G. (1992). Chinatown: A portrait of a closed society. HarperCollins.

[7] Hatziprokopiou, P., \& Montagna, N. (2012). Contested Chinatown: Chinese migrants' incorporation and the urban space in London and Milan. Ethnicities, 12(6), 706-729.

[8] Lasagabaster, D (2010) Australia's language potential. International Journal of Multilingualism 7(2): 187-190.

[9] Pennycook, A., \& Otsuji, E. (2015). Metrolingualism: Language in the city. Routledge.

[10] Skinner, G. W. (1971). Chinese peasants and the closed community: An open and shut case. Comparative Studies in Society and History, 13(3), 270-281.

[11] Tarantino, M. (2009). THE BATTLE OF MILAN: SOCIAL REPRESENTATIONS OF THE APRIL 2007 RIOTS BY TWO CHINESE COMMUNITIES MATTEO TARANTINO AND SIMONE TOSONI. Living outside the walls: The Chinese in Prato, 202.

[12] The latest census in Australia: Chinese and Asian-Indian have been the main immigrants? (2017.June 8).from BBC Chinese: http://www.bbc.com/zhongwen/simp/40427029

[13] Wood, P \& C Landry (2008). The intercultural city. London: Earthscan

[14] Yan, XP. Bao, HL\& Zhen, T. (2015). The study of overseas Chinese education in Italy set the Chinese language and culture schools founded by Wenzhounese in Italy as the cases. Zhejiang University Press

[15]Zhou, M. (2009). Contemporary Chinese America: Immigration, ethnicity, and community transformation. Temple University Press. 